\title{
Brazilian adolescents' food and beverages choices during school break: The Brazilian School Meal Program or food from other establishments?
}

\author{
Ana Carolina Leme*, Sonia Tucunduva Philippi, Erika Christiane Toassa \\ Department of Nutrition, School of Public Health, University of São Paulo, São Paulo, Brazil; \\ *Corresponding Author: leme.acarolina@usp.br
}

Received 31 January 2012; revised 28 February 2012; accepted 16 March 2012

\begin{abstract}
The purpose of this study was to identify the adolescents' food preferences during school break. This was a qualitative cross-sectional study with 83 adolescents from a public school in the city of São Paulo. The participants answered the following question: During the school break do you usually eat or drink something? Please justify your answer. The adolescents' answers were analyzed through a Brazilian qualitative technique called Discourse of the Collective Subject. The ideas were: School Meal Program (36.2\%), don't eat anything (26.7\%), bring from other establishments (20.1\%) and drink water or juice $(17.1 \%)$. The adolescents who chose the School Meal Program claimed they had no other options. On the other hand, the participants who refused the meal did so because they disliked it and as a result brought snacks from home or food markets. The Discourse of the Collective Subject helps the investigator to understand the ideas related to food and nutrition of a collectivity.
\end{abstract}

Keywords: Adolescents; Food Choices; School Meal Program; Competitive Foods; Qualitative Research

\section{INTRODUCTION}

Several studies have demonstrated that the adolescents' diet is inadequate, not meeting the dietary recommendations and guidelines. It is characterized by foods and beverages rich in fat and sugar such as corn and potato chips, finger foods, cookies, candies, soft drinks and artificial juice. On the other hand, there is a low intake of fruits, vegetables, whole grains, fiber and milk [1-4]. These dietary patterns are a matter of concern for their potential risk for obesity and chronic noncommunicable diseases such as cardiovascular diseases, diabetes and cancer $[3,4]$.

The youth eating patterns are influenced by several factors such as individual food preferences, family meal patterns and parental role modeling. Nonetheless, it has become clear that this population's eating habits are also determined by media messages and social norms [5].

Since adolescents spend a significant amount of time in school, this environment can have an influence on their eating patterns. School age individuals spend at least 6 hours at school every weekday where they consume on average $35 \%$ of their daily food intake, and expend up to $50 \%$ of their daily energy $[6,7]$.

Foods and beverages at school are classified into two main categories: The Government School Meal Program and foods and beverages consumed outside the formal meal program, especially à la carte items available in the school cafeteria and venues outside the cafeteria, as vending machines, food markets near school and foods and beverages brought from home. The latter are known as competitive foods due to the fact that they compete with the school meal program [8].

The Brazilian School Meal Program is a governmental policy aimed at supplying at least $15 \%$ of the nutritional requirements of the students enrolled in public schools during their day at school. Furthermore, this program targets on reducing the school dropout rates, building healthy eating habits and increasing the learning ability [9].

Although the meal offered by the government is free, many of the Brazilian fundamental and high school students consume competitive foods which are generally high in fat and sugar [10,11].

Thus, this paper aims to identify the adolescents' food preferences: the Brazilian School Meal Program or the competitive foods through a qualitative technique. Also, this study seeks to identify their opinions and the reasons behind their choices. 


\section{METHODS}

A qualitative method is used to collect data through descriptions of topics of interest [12]. An open question is carried out, in which the participants are free to express opinions, beliefs, meanings and thoughts as to how they experience their social and cultural world and so the data are detailed, comprehensive, more representative of the phenomenon, and less biased [13].

The Discourse of the Collective Subject (DCS) was the method chosen to analyze the data from this survey. This technique is a Brazilian method based on the Theory of the Social Representation which is an explicit proposal for reconstituting an empirical collective being or entity, stating the individual opinion as a subject of the discourse spoken in the first person singular [14].

In fact, opinions or social representations are efficient. That means they work, precisely because individuals believe that these are their opinions, generated in their brains. Thus, the DCS consists of collecting the individual answers from a discursive question and clustering the answers that have same, similar or complementary ideas together to built one singular discourse [14]. Summarizing, the DCS is as if one person were representing a collectivity.

\subsection{Study Design and Sample}

This was a cross-sectional study conducted in the second semester of 2009 involving adolescents of both genders, ranging from 10 to 16 years of age and who were enrolled in a public school in the city of São Paulo. The students voluntarily participated in the study. Prior to the acceptance, children's parents or guardians were fully informed about the objectives and methods of the study and signed an informed consent. The majority of the adolescents assigned for the study participated in it. Only a few were not present on the day of the interview or didn't bring the consent signed by their parents or guardians.

\subsection{Data Collection}

Students through 5th and 8th grades of fundamental school were invited to participate in the study. Because the technique used to analyze the data was a Brazilian qualitative method that didn't require a big sample, one class of each grade was selected for the survey (Figure 1). A selection of the most relevant characteristics of the population was thus obtained for the study. Since the students in each class differed in age and gender, they could compose a diverse and representative sample for this study, and consequently for the discourse construction [15].

\subsection{Pre-Test}

The question used in this survey was previously tested in a similar sample of adolescents (age and gender). After the pre test, some adjustments were made to the format of the question adapting it to the aim of the study.

\subsection{Interview with the Adolescents}

A discursive question was proposed in order to get to know the adolescents' preferences and food choices during school break (Box 1). The students were free to give their own opinion related to the topic.

The participants were informed about the interview content and were free to address the issues in their own way. They were also informed that were no right or wrong answers. They were accommodated in a comfortable way to answer the question during Physical Education class.

\subsection{Data Analysis}

For the data analysis the Discourse of the Collective Subject (DCS) was used as a methodological resource to rescue collectivity opinions in a quali-quantitative way. This technique allows for a particular social group to express a given thought or social representation about a

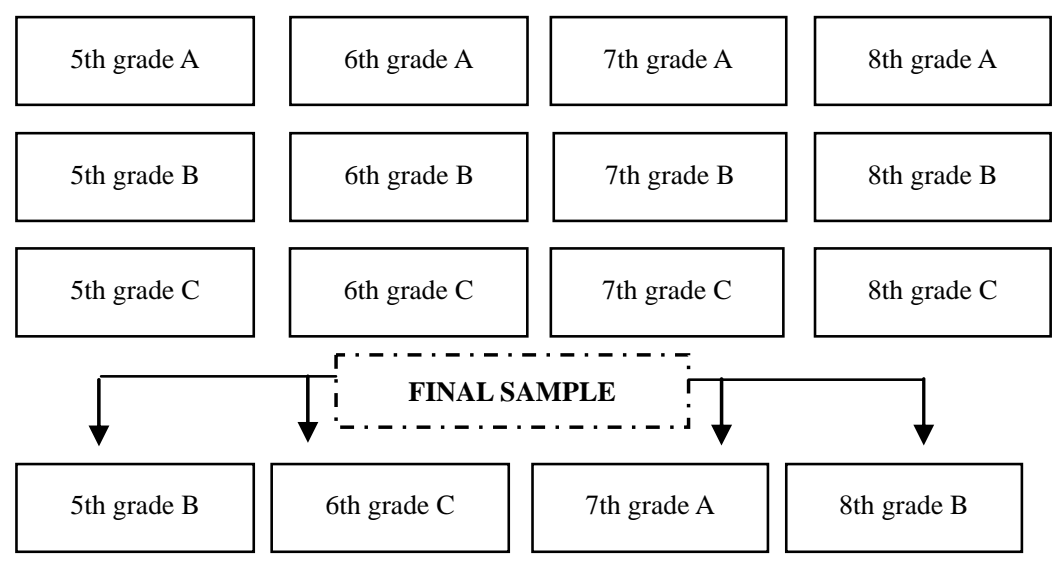

Figure 1. Selection of adolescents. 
Question: During the school break do you usually eat or drink something? Please justify your answer.

Aim: To identify the adolescents' food choices and preferences during school break, as well as the reasons for their choices.

Box 1. Discursive question used in this study and its aim.

phenomenon [14].

The discursive data was assessed by the following methodological figures: key expressions and central ideas selected from each individual answer to the question. The key expressions are the most significant excerpts of the answers, and correspond to the central ideas. The central ideas are the synthesis of the discursive content expressed in these key expressions. The synthesis of the discourse is built from a varied number of individuals in the first person of the singular. These results become the Discourse of the Collective Subject (DCS). In Box 2 the steps to develop the DCS are shown (adapted from LEME et al. [15].

\subsection{Ethical Aspects}

The study procedures were approved by the School of Public Health, University of São Paulo Ethic Committee and by the principal of the participating school. Adolescents were allowed to participate in the study provided that they brought their parents or guardians' signature on the consent term, which also explained the aims of the study briefly.

\section{RESULTS}

83 adolescents participated in this study. 33 (39.8\%) of them were boys and 50 (60.2\%) were girls between ages 10 and 16. As to the proportion of participants in each grade according to gender, the majority of girls were enrolled in $7^{\text {th }}$ grade (34.62\%) and the majority of boys in $5^{\text {th }}$ grade $(29.03 \%)$.

The teenagers' answers generated 105 key expressions that resulted in 4 central ideas: School Meal Program, Don't eat anything, Bring from other establishments and Drink water or juice. These ideas produced the Discourse of the Collective Subject representing the food choices and preferences of the population studied (Table 1).

The key expressions generated the central ideas which resulted in the students' discourses about healthy eating (Box 3).

\section{DISCUSSION}

The results of this survey indicate that most of the adolescents consider the Brazilian School Meal Program important. However, this is not a condition to control their school dropout rates [16]. Moreover, most of the
1) The answers were analyzed separately. The whole content of each answer was copied.

2) The key-expressions were identified.

3) The central ideas in the key-expressions were identified.

4) The central ideas that had the same, similar or complementary meanings were identified and clustered. Each cluster was categorized with letters A, B, C (...).

5) Each cluster of the categories A, B, C (...) resulted in the Discourse of the Collective Subject.

Box 2. Steps for the development of the DCS.

Table 1. Proportion of central ideas.

\begin{tabular}{cc}
\hline School Meal Program & $36.2 \%$ \\
Don't eat anything & $26.7 \%$ \\
Bring from other establishments & $20 \%$ \\
Drink water or juice & $17.1 \%$ \\
\hline
\end{tabular}

\section{School Meal Program}

"I try to eat the food served by the School Meal Program because it is what the school offers us. Our school doesn't have a canteen that sells different foods and beverages. If I don't eat at school I can be very hungry before I arrive home. Moreover, the meal is usually balanced and healthy. During the morning rice, beans, meat and vegetables are offered and in the afternoon bread, cookies, yogurt and juice”.

\section{Don't eat anything}

"I don't eat anything. The school meal is yucky, I don't like it. Furthermore, I'm not used to eating rice and beans at $10 \mathrm{am}$. My school is located in a low income neighborhood and the meal offered is always the same. That's why I'd rather eat at home. I think the school meal should be changed. There should be more natural juice because it is healthy. Before and after school I have a full meal at home".

\section{Bring from other establishments}

"Sometimes I bring food and beverages or money from home. When I bring money I go to food markets near my school to buy a package of sandwich cookies, corn or potato chips, hot dogs, soft drinks, candies, lollipops and gum. Those are the foods I like the taste of. On the other hand, when I bring food from home, I usually eat fruit (apple), vegetables, whole wheat bread with lean cheese, cereal and granola. Foods brought from home are healthier. I usually drink a lot of water and juice".

\section{Drink water or juice}

"I'm used to drinking a lot of water during school break to keep hydrated, but I sometimes drink juice”.

Box 3. Central ideas resulted in the students' discourses about healthy eating.

students refer to consume foods and beverages from other establishments. The foods and beverages in their speeches have a high content of fat and sugar as it is mentioned in the following discourse: “(...) a package of sandwich cookies, corn or potato chips, hot dogs, soft drinks, candies, lollipops and gum". 
This choice can be related to factors such as taste and attraction to foods and beverages sold in commercial establishments [11] as shown in the following speech "Those are the foods I like the taste of". Other important factors related to their inadequate food choices are the social barriers as peer pressure, as well as a lack of parental/school support and modeling of healthy eating behaviors [17-19].

However, many of these barriers are not an issue in our study. In the participants' speeches healthy food choices brought from home are mentioned: "On the other hand, when I bring food from home, I usually eat fruit (apple), vegetables, whole wheat bread with lean cheese, cereal and granola. Foods brought from home are healthier". The same was observed in the study of Harrison \& Jackson [18] where there is a strong family interest in healthy eating. Nonetheless, it does point out to the important role of the family and the home on healthy eating, particularly when leisure involves foods rich in fat and sugar. Moreover, the proportion of adolescents who engage in family meals decreases with age due to an increased desire for independence from the family as teenagers become older.

According to the adolescents' speeches in the current study the greater consumption of unhealthy foods and beverages at school can be associated to their access to money and freedom to purchase sweets and snack foods at school. However, as far as children's food choices are concerned, school was not recognized as an important influence especially because they reported bringing packed lunches to school [20].

Teenagers may have a less healthy diet when eating out with peers or at school because they have more nutriational autonomy in these situations and can make choices for themselves. As adolescents gain more control over their food choices, cost becomes an important factor often leading to less healthy eating [20].

The place where the meals are taken may be equally important. Students with poor quality diet are signifycantly more likely to consume meals and snacks away from home than students with either average or superior quality diet. The type of location where the meal or snack is consumed did not necessarily matter; those with an inadequate diet reported buying food in markets near school or in school canteens. On the other hand, those with a more adequate diet reported bringing it from home or eating the meal offered by the school program [21-23]. At this stage of life, however, the consumption of food items sold in stores near schools does not necessarily have a significant effect on student weight gain. This situation might be changed in adulthood [22].

The distance to the nearest food market may be an important determinant for the consumption of salty and fatty snacks, sweet beverages and sweeties. This might indicate that the adolescents consider 300 meters too far to walk and do not visit these establishments to buy these foods and beverages [24]. Thus, the distance to walk to a food store can be related to the adolescents' sedentary behaviors. It seems that youth are even less active and opting for wrong food choices [25,26] requesting lack of preparation and ease to consume [18,27].

The time constraint associated with being a student, makes it difficult to obtain or prepare healthful meals and to exercise. Youth perceived that unhealthy food and beverages consumed during the school day contributed to overeating and made it difficult to eat healthy and maintain an adequate weight [27].

The School Meal Program should function as an important nutritional strategy to promote adequate food habits. If children and adolescents are not stimulated by tasty, attractively and nutritionally adequate food preparations, the meals offered daily will not be well accepted and healthy food habits will not be incorporated [16].

The adolescents who consumed the food and beverages served by the governmental program claimed that the school did not have canteens for them to purchase different items and complained about getting too hungry by the time they arrived home. Sturion et al. and Flávio et al. also observed that the presence of canteens and food stores at school is an important determinant for the rejection to the School Meal Program [10,28].

A great amount of Brazilian adolescents attend school in the morning. Nevertheless, the foods that are offered by the school meal program between 9:30 and 10 am compose a typical Brazilian lunch: rice, beans, meat and vegetables, which the students refuse to eat. At that time they would prefer to have a lighter meal with foods and beverages of their taste [11,16,29,30].

The students' wrong food choices associated with their sedentary habits can have as consequence the weight gain. This situation can be consolidated during adulthood. The school should act as an agent to prevent inadequate nutrition providing students with food and nutrition education. Conversely, the adolescent can be an important agent on family and community behaviors [31].

The availability of healthy foods items within school meals may not be enough to influence the students' consumption. Efforts are needed not only to increase the availability and accessibility of healthy foods and beverages, but may also to educate adolescents on appropriate food choices within and among food groups [7].

\section{CONCLUSION}

The Discourse of the Collective Subject is a qualitative method that helps the investigator to understand the ideas related to food and nutrition of a collectivity, in this case the adolescents' collectivity. It represents the col- 
lectivity studied. In this method large samples are not required, due to the fact that the populations' characteristics can be obtained through the main features of the discourse of the individuals studied. In other words, the sample required by the authors [14] of this technique varies from 60 to 150 subjects. In our study, the main relevant characteristics of the population were gender and age so we decided to study one of the three classes of each grade of school curricula.

In this sense, these findings represent the ideas generated from the adolescents of the community studied located in a low income area of São Paulo. Although the students did not like the food offered by the Brazilian governmental program, most of them consumed it for the lack of other options. Nonetheless, it was not uncommon for them to buy the foods of their preference in establishments near school or even to bring snacks from home.

To enhance their adherence to the Brazilian School Meal Program changes should be made to it. The composition of the meal should be adapted to their preferences and taste. Also, healthy preparations should be incorporated. Furthermore, nutritional education strategies should be put into practice involving all the school community-the students, school staff and family members. The work to be done ought to focus on food behave- ioral changes and motivation enhancement in order to incorporate healthy habits that can be consolidated into adulthood and bring along a better quality of life in this community studied.

\section{REFERENCES}

[1] Leal, G.V.S., Philippi, S.T., Matsudo, S.M.M. and Toassa, E.C. (2010) Consumo alimentar e padrão de refeições de adolescentes, São Paulo, Brasil. Revista Brasileira de Epidemiologia, 13, 457-467. doi:10.1590/S1415-790X2010000300009

[2] Diethelm, K., et al. (2011) Food intake of European adolescents in the light of different food base dietary guidelines: Results of the HELENA (Healthy Lifestyle in Europe by Nutrition in Adolescence) Study. Public Health Nutrition, 22, 1-13.

[3] Matthews, V.L., Wien, M. and Sabaté, J. (2011) The risk of child and adolescent overweight is related to types of food consumed. Nutrition Journal, 24, 71. doi:10.1186/1475-2891-10-71

[4] Dishchekenien, V.R.M., Escrivão, M.A.M.S., Ancona-Lopez, F., Araújo, E.A.C. and Taddei J.A.A.C. (2011) Padrões alimentaresde adolescentes obesos e diferentes repercusões metabólicas. Revista de Nutrição, 24, 17-29.

[5] Neumark-Sztainer, D., French, S.A., Hannan, P.J., Story M. and Fulkerson, J.A. (2005) School lunch and snacking patterns among high school students: Associations with school food environment and policies. International Journal of Behavioral Nutrition and Physical Activity, 2, 14. doi:10.1186/1479-5868-2-14

[6] Briefel, R.R., Crepinsek, M.K., Cabili, C., Wilson, A. and Gleason, P.M. (2009) School food environments and practices affect dietary behaviors of US Public School Children. Journal of the American Dietetic Association, 109, S91-S107. doi:10.1016/j.jada.2008.10.059

[7] Condon, E.M., Crepinsek, M.K. and Fox, M.K. (2009) School meals: Types of foods offered to and consumed by children at lunch and breakfast. Journal of the American Dietetic Association, 109, S67-S78. doi:10.1016/j.jada.2008.10.062

[8] Story, M., Nanney, M.S. and Schwartz, M.B.(2009) Schools and obesity prevention: Creating school environments and policies to promote healthy eating and physical activity. The Milbank Quarterly, 87, 71-100. doi:10.1111/j.1468-0009.2009.00548.x

[9] Brasil (2012) Ministério da Educação. Fundo Nacional de Desenvolvimento da Educação. Alimentação Escolar (Access on 3 December 2011). http://www.fnde.gov.br/

[10] Sturion, G.L., Silva, M.V., Ometto, A.M.H., Furtuoso, M.C.O. and Piptone, M.A.P. (2005) Fatores condicionantes da adesão dos alunos ao Programa de Alimentação Escolar no Brasil. Revista de Nutrição, 18, 167-181.

[11] Ochsenhofer, K., Quintella, L.C.M., Silva, E.C., Nascimento, A.P.B., Ruga, G.M.N.A., Philippi, S.T. and Szarfac, S.C. (2006) O papel da escola na formação da escolha alimentar: Merenda escolar ou cantina? Nutrire: Revista da Sociedade Brasileira de Alimentação e Nutrição, 31, 1-16.

[12] Taylor, M.C. (2005) Interviewing. In: Holloway, E.D. Ed., Qualitative research in health care, Open University Press, New York, 2005, pp. 39-55.

[13] Harris, J., et al. (2009) An introduction to qualitative research for food and nutrition professionals. Journal of the American Dietetic Association, 9, 80-90. doi:10.1016/j.jada.2008.10.018

[14] Lefèvre, F. and Lefèvre, A.M.C. (2007) The collective subject that speaks. Interface-Comunicação, Saúde e Educação, 3, 517-524.

[15] Leme, A.C.B., Philippi, S.T. and Silva, E.C.T. (2011) Associations of Brazilian adolescents with healthy eating: Knowledge, perceptions and food choices. Food and Nutrition Sciences, 2, 1036-1042.

[16] Muniz, V.M. and Carvalho, A.T. (2007) O Programa Nacional de Alimentação Escolar em município do estado da Paraíba: um estudo sob o olhar dos beneficiários do Programa. Revista de Nutrição, 20, 285-296.

[17] Neumark-Sztainer, D., Story, M., Perry, C. and Casey, M.A. (1999) Factors influencing food choices of adolescents: Findings from focus-group discussions with adolescents. Journal of the American Dietetic Association, 99, 929-937. doi:10.1016/S0002-8223(99)00222-9

[18] Harrison, M. and Jackson, L.A. (2009) Meanings that youth associate with healthy and unhealthy food. Canadian Journal of Dietetic Practice and Research, 70, 6-12.

[19] Protudjer, J.L.P., et al. (2010) Children's perceptions of healthful eating and physical activity. Canadian Journal of Dietetic Practice and Research, 71, 19-23. doi:10.3148/71.1.2010.19 
[20] Fitzgerald, A., Heary, C., Nixon, E. and Kelly, C. (2010) Factors influencing the food choices of Irish children and adolescents: A qualitative investigation. Health Promotion International, 25, 289-298. doi:10.1093/heapro/daq021

[21] Storey, K.E., Hanning, R.M., Lambraki, I.A., Driezen, P., Fraser, S.N. and McCargar, L.J. (2009) Determinants of diet quality among Canadian Adolescents. Canadian Journal of Dietetic Practice and Research, 70, 58-65.

[22] Harris, E.D. et al. (2011) Locations of food stores near schools does not predict weight status of Maine High School Students. Journal of Nutrition Education and Behavior, 43, 274-278. doi:10.1016/j.jneb.2010.08.008

[23] Potti, J.M. and Popkin, B.M. (2011) Trends in energy intake among US children by eating location and food source, 1977-2006. Journal of the American Dietetic Association, 111, 1156-1164. doi:10.1016/j.jada.2011.05.007

[24] Van Der Horst, K., Timperio, A., Crawford, D., Roberts, R., Brug, J. and Oenema, A. (2008) The Association food environment: Associations with adolescent soft drink and snack consumption. American Journal of Preventive Medicine, 35, 217-222. doi:10.1016/j.amepre.2008.05.022

[25] Enes, C. and Slater, B. (2010) Obesidade na adolescência e seus principais fatores determinantes. Revista Brasileira de Epidemiologia, 13, 163-171. doi:10.1590/S1415-790X2010000100015

[26] Pate, R.R., Mitchell, J.A., Byun, W. and Dowda, M. (2011) Sedentary behavior in youth. British Journal of Sports Medicine, 45, 906-913. doi:10.1136/bjsports-2011-090192

[27] Greaney, M.L., et al. (2009) College students' barriers and enablers for healthful weight management: A qualitative study. Journal of Nutrition Education and Behavior, 41, 281-286. doi:10.1016/j.jneb.2008.04.354

[28] Sturion, G.L., et al. (2005) Fatores condicionantes da adesão dos alunos os Programa de Alimentação Escolar no Brasil. Revista de Nutrição, 18, 167-181.

[29] Flávio, E.F., Barcelos, M.F.P., Cirillo, M.A. and Ribeiro, A.H. (2008) Avaliação da alimentação escolar oferecida aos alunos do ensino fundamental das escolas municipais de Lavras, MG. Ciencia E Agrotecnologia, 32, 1879-1887.

[30] Martins, R.C.B., Medeiros, M.A.T., Ragonha, G.M., Olbi, J.H., Segatti, M.E.P. and Osele, M.R. (2004) Aceitabilidade da alimentação escolar no ensino público fundamental. Saúde em Revista, 6, 71-78.

[31] Bezerra, J.A.B. (2009) Alimentação e escola: Significados e implicações curriculares da merenda escolar. Revista Brasileira de Educação, 14, 103-115. doi:10.1590/S1413-24782009000100009 